PACS: 02.81

\title{
LONGITUDINAL-FLEXURAL SELF-SUSTAINED VIBRATIONS OF NANOTUBE CONVEYING FLUID
}

\author{
K. Avramov \\ National Academy of Science of Ukraine, Podgorny Institute for Mechanical Engineering, Department of Vibrations \\ 2/10 Pozharskogo St., 61046, Kharkiv, Ukraine \\ E-mail: kvavr@kharkov.ua, https://orcid.org/0000-0002-8740-693X \\ Received June 21 2018; accepted 14 September 2018
}

Beam model of geometrical nonlinear longitudinal-flexural self-sustained vibrations of nanotube conveying fluid is obtained with account of nonlocal elasticity. The Euler-Bernoulli hypotheses are the basis of this model. The geometrical nonlinear deformations are described by nonlinear relations between strains and displacements. It is assumed, that the amplitudes of the longitudinal and bending vibrations are commensurable. Using variational methods of mechanics, the system of two nonlinear partial differential equations is derived to describe the nanotube self-sustained vibrations. The Galerkin method is applied to obtain the system of nonlinear ordinary differential equations. The harmonic balanced method is used to analyze the monoharmonic vibrations. Then the analysis of the self-sustained vibrations is reduced to the system of the nonlinear algebraic equations with respect to the vibrations amplitudes. The Newton method is used to solve this system of nonlinear algebraic equations. As a result of the simulations, it is determined that the stable self-sustained vibrations originate in the Hopf bifurcation due to stability loss of the trivial equilibrium. These stable vibrations are analyzed, when the fluid velocity is changed. The results of the self- sustained vibrations analysis are shown on the bifurcation diagram. The infinite sequence of the period-doubling bifurcations of the monoharmonic vibrations is observed. The chaotic motions take place after these bifurcations. As a result of the numerical simulations it is determined, that the amplitudes of the longitudinal and flexural vibrations are commensurable.

KEY WORDS: longitudinal-flexural self-sustained vibration, sequence of period-doubling bifurcations, chaotic self-sustained vibration, Hopf bifurcation

\section{ПОЗДОВЖНІ - ЗГИНАЛЬНІ АВТОКОЛИВАННЯ НАНОТРУБОК ТРАНСПОРТУЮЧИХ РІДИНУ \\ К. Аврамов}

Національна академія наук Украӥни, Інститут проблем машинобудування ім. А.М. Підгорного вул. Д. Пожарського 2/10, Харків 61046, Україна

Ураховуючи нелокальну пружність, у статі отримано модель поздовжньо - згинальних автоколивань нанотрубок транспортуючих рідину при геометрично нелінійному деформуванні. Гіпотези Ейлера - Бернуллі є засадами цій моделі. Геометрично нелінійне деформування описується нелінійним зв'язком між деформаціями та переміщеннями нанотрубки. При виведені моделі припускалося, що амплітуди повздовжніх та згинальних коливань сумірні. Використовуючи варіаційні методи механіки, отримано систему двох нелінійних рівнянь у часткових похідних відносно повздовжніх та поперечних переміщень, які описують автоколивання нанотрубок. За допомогою методу Галеркіна отримано систему нелінійних звичайних диференційних рівнянь, які описують автоколивання. Моногармонічні автоколивання досліджуються методом гармонічного балансу. Аналіз автоколивань зводиться до системи нелінійних алгебраїчних рівнянь відносно амплітуд автоколивань. Така система нелінійних рівнянь вирішується за допомогою методу Ньютона. У результаті чисельного модулювання встановлено, що при втраті стійкості тривіального положення рівноваги внаслідок біфуркацій Хопфа виникають стійкі автоколивання, які досліджуються при зміні швидкості руху рідини по нанотрубці. Результати цього аналізу наводяться на біфуркаційній діаграмі. У системі спостерігається нескінчена послідовність біфуркацій подвоєння періоду моно гармонічних автоколивань. Після цій послідовності біфуркацій спостерігаються хаотичні рухи. У результаті чисельного моделювання встановлено, що амплітуди повздовжніх та згинальних коливань сумірні.

КЛЮЧЕВЫЕ СЛОВА: поздовжньо-згинні автоколивання, послідовність біфуркацій подвоєння періоду, хаотичні автоколивання, біфуркація Хопфа

\section{ПРОДОЛЬНО-ИЗГИБНЫЕ АВТОКОЛЕБАНИЯ НАНОТРУБКИ ТРАНСПОРТИРУЮЩЕЙ ЖИДКОСТЬ К. Аврамов}

Нациинальная академия наук Украины, Институт проблем машиностроения им. А.Н. Подгорного

$$
\text { ул. Пожарского 2/10, Харьков 61046, Украина }
$$

Учитывая нелокальную упругость, в статье представлена модель продольно-изгибных автоколебаний нанотрубки транспортирующей жидкость при ее геометрически нелинейном деформировании. Гипотезы Эйлера- Бернулли являются основой этой модели. Геометрически нелинейное деформирование описывается нелинейной связью между деформациями и перемещениями нанотрубки. При выводе модели предполагалось, что амплитуды продольных и изгибных колебаний соизмеримы. Используя вариационные методы механики, получена система двух нелинейных уравнений в частных производных относительно продольных и поперечных перемещений, описывающая автоколебания нанотрубки. С помощью метода Галеркина выведена система нелинейных обыкновенных дифференциальных уравнений, описывающая автоколебания. Моногармонические автоколебания нанотрубки исследуются методом гармонического баланса. Тогда анализ автоколебаний сводится к системе нелинейных алгебраических уравнений относительно амплитуд автоколебаний. Такая система нелинейных алгебраических уравнений решается методом Ньютона. В результате численного моделирования установлено, что при потере устойчивости тривиального состояния равновесия вследствие бифуркации Хопфа образуются устойчивые автоколебания, которые исследуются при изменении скорости движения жидкости по нанотрубке. Результаты 
такого анализа представляются на бифуркационной диаграмме. В системе наблюдается бесконечная последовательность бифуркаций удвоения периода моногармонических автоколебаний. После этой последовательности бифуркаций наблюдаются хаотические автоколебания. В результате численного моделирования установлено, что амплитуды продольных и изгибных колебаний соизмеримы.

КЛЮЧЕВЫЕ СЛОВА: продольно-изгибные автоколебания, последовательность бифуркаций удвоения периода, хаотические автоколебания, бифуркация Хопфа

Carbon nanotubes are macromolecules of carbon with a cylindrical shell shape. These tubes are used for a variety of technological and biomedical applications including nano-pipes conveying fluids. The moving fluid causes the structural instability and the self-sustained vibrations of nanotubes. The linear model of the nanotube conveying fluid, which are based on the Euler-Bernoulli beam theory, are treated in the papers [1-6]. The effect of the fluid velocity on the nanotube eigenfrequencies is analyzed. Wang, Lee, Chang [7, 8] derive the model of the vibrations of the nanotube conveying fluid accounting nonlocal elasticity and the Euler-Bernoulli beam theory. The critical velocities of the fluid are analyzed. Lee, Chang and others $[9,10]$ suggest the model of the nanotube vibrations in the elastic medium. The vibrations of nanotube conveying fluid are analyzed by Chang, Lee [11] using the Timoshenko beam model.

The shell models, which are based on the Donnell theory and the nonlocal elasticity, are used to model the double walled carbon nanotubes vibrations in the papers $[12,13]$. The dynamic instability is analyzed. The model of vibrations of triple-walled carbon nanotubes (CNT) conveying fluid is obtained on the basis of the Euler-Bernoulli beam model in the paper [14]. The model of the vibrations of the multi walled carbon nanotubes conveying fluid is derived in the paper [15]. The Timoshenko beam model is used to describe the multi-walled carbon nanotubes conveying fluid by Khosravian, Rafii-Tabar [16]. The dependence of the eigenfrequencies on the fluid velocity is analyzed.

The model of the flexural - longitudinal self-sustained vibrations of the nanotube is derived in the present paper. This model takes the form of the system of nonlinear ordinary differential equations, which describe the geometrical nonlinear vibrations of the nanotube. The system of the differential equations is derived from the system of two partial differential equations, which describe the flexural- longitudinal self-sustained vibrations of the nanotube conveying fluid. The derivation of the model of the flexural-longitudinal self-sustained vibrations is the novelty of the present paper.

The aim of the paper is analysis of the bifurcation behavior of the self-sustained vibrations of the nanotube conveying fluid. The significant longitudinal vibration, which accompanies the flexural vibrations, is detected. This is the novelty of this paper. Moreover, it is obtained, that the periodic monoharmonic self-sustained vibrations undergo the infinite sequence of the period- doubling bifurcations. Then these motions are transformed into the chaotic ones.

\section{MAIN EQUATIONS}

The cantilever nanotube conveying fluid is considered (Fig.1). Following the papers [1, 3, 8], analysis of the nanotube conveying fluid dynamics is reduced to modeling of very small dimension mechanical pipe vibration. The length of the nanotube is $L$. The mass per unit length and the flexural stiffness are denoted by $m$ and $E I$, respectively. The fluid is moved with constant velocity $U_{*}$. The nanotube is directed lengthwise $x$ axis. The nanotube vibrations take place in the plane $(x, y)$. The projections of the displacements on the $x$ and $y$ axes are denoted by $u(s, t)$ and $v(s, t)$, where $s$ is arc length of the nanotube neutral line.

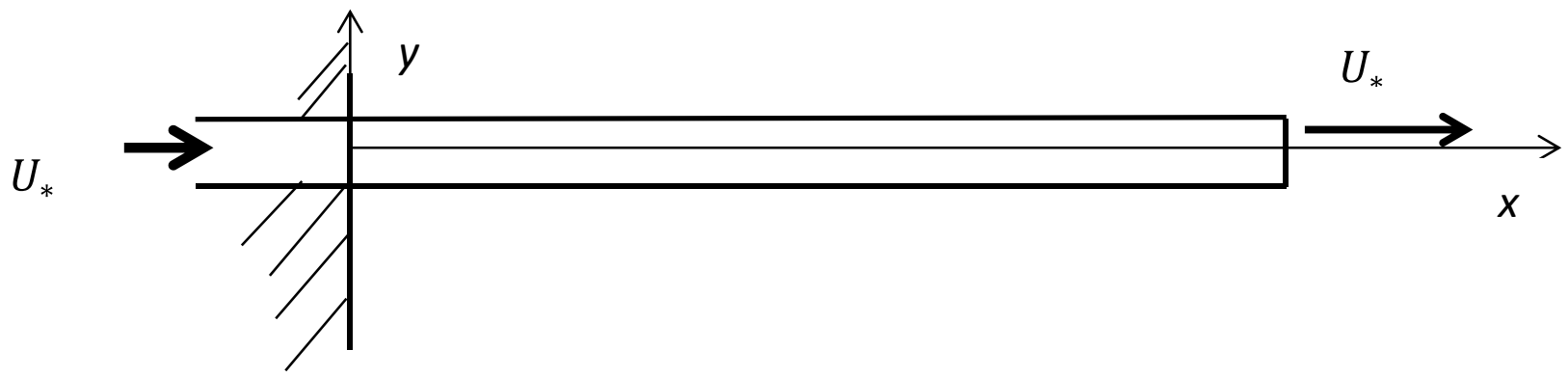

Fig.1. Outline of nanotube conveying fluid.

The nanotube diameter is significantly less, then its length. Therefore, the Euler-Bernoulli theory is used in the subsequent analysis. Thus, the shear and rotatory inertia are not accounted. The nonlocal elasticity is accounted in the nanotube model $[17,18]$. It is assumed, that the strains are small and the displacements are moderate. Then the nanotube performs the geometrically nonlinear vibrations.

The cantilever nanobeam satisfies the following boundary conditions:

$$
\left.v\right|_{s=0}=\left.\frac{\partial v}{\partial s}\right|_{s=0}=\left.u\right|_{s=0}=0 ;\left.\quad M\right|_{s=L}=\left.Q\right|_{s=L}=\left.\frac{\partial u}{\partial s}\right|_{s=L}=0,
$$

where $M$ is resultant bending moment; $Q$ is resultant shear force. 
The Hamilton's principle is applied to derive the equations of the nanotube motions. It takes the following form for the cantilever nanotube $[19,20]$ :

$$
\delta \int_{t_{1}}^{t_{2}} \mathcal{L} d t=\int_{t_{1}}^{t_{2}}\left[M_{1} U_{*}\left(\frac{\partial \vec{r}_{L}}{\partial t}+U_{*} \vec{\tau}_{L}^{0}\right) \cdot \delta \vec{r}_{L}\right] d t
$$

where $\mathcal{L}$ is Lagrange function, which has the form: $\mathcal{L}=T_{F}+T_{1}-\prod_{1}, T_{F}-$ is kinetic energy of the moving fluid; $T_{1}, \Pi_{1}$ are kinetic and potential energies of the nanotube; $t_{1}, t_{2}$ are initial and final instances of time; $M_{1}$ is mass per unit length of the moving fluid; $\vec{r}_{L}$ is radius-vector of the end of the nanotube neutral line; $\vec{\tau}_{L}^{0}$ is unit tangent vector to the neutral line at $x=L$.

The deformed neutral line of the nanotube is considered. Then its position is described by the radius-vector [14]: $\vec{r}=(s+u) \vec{\imath}^{0}+v \vec{\jmath}^{0}$, where $\vec{\imath}^{0}, \vec{j}^{0}$ are unit vectors of the axes $x, y$. The unit tangential vector to the neutral line $\vec{\tau}^{0}$ takes the form: $\vec{\imath}^{0}=\frac{\partial \vec{r}}{\partial s}=\left(1+\frac{\partial u}{\partial s}\right) \vec{\imath}^{0}+\frac{\partial v}{\partial s} \vec{\jmath}^{0}$.

The variation of the potential energy of the nanotube is the following:

$$
\delta \prod_{1}=\int_{0}^{L}[N \delta \varepsilon+M \delta k] d s,
$$

where $N$ is resultant longitudinal force; $\varepsilon$ is longitudinal strain of the neutral line; $k$ is curvature of the neutral line. The longitudinal strain takes the form: $\varepsilon=\frac{\partial u}{\partial x}+0.5\left(\frac{\partial v}{\partial x}\right)^{2}=\frac{\partial u}{\partial s}+\left(\frac{\partial u}{\partial s}\right)^{2}+0.5\left(\frac{\partial v}{\partial s}\right)^{2}$. The curvature of the neutral line is determined as:

$$
k=\frac{\partial^{2} v}{\partial s^{2}}+0.5\left(\frac{\partial v}{\partial s}\right)^{2} \frac{\partial^{2} v}{\partial s^{2}}
$$

The variation of the potential energy has the form:

$$
\delta \prod_{1}=\int_{0}^{L} \delta v\left\{\frac{\partial^{2} M}{\partial s^{2}}+\frac{\partial^{2}}{\partial s^{2}}\left[\frac{M}{2}\left(\frac{\partial v}{\partial s}\right)^{2}\right]-\frac{\partial}{\partial s}\left[N \frac{\partial v}{\partial s}\right]-\frac{\partial}{\partial s}\left[M \frac{\partial^{2} v}{\partial s^{2}} \frac{\partial v}{\partial s}\right]\right\} d s+\int_{0}^{L} \delta u\left[-\frac{\partial N}{\partial s}-\frac{\partial}{\partial s}\left(2 N \frac{\partial u}{\partial s}\right)\right] d s .
$$

The velocity of the nanotube motions is the following: $\vec{V}_{P}=\frac{\partial u}{\partial t} \vec{\imath}^{0}+\frac{\partial v}{\partial t} \vec{j}^{0}$. The variation of the kinetic energy takes the form:

$$
\delta \int_{t_{1}}^{t_{2}} T_{1} d t=-m \int_{t_{1}}^{t_{2}} \int_{0}^{L}\left[\frac{\partial^{2} u}{\partial t^{2}} \delta u+\frac{\partial^{2} v}{\partial t^{2}} \delta v\right] d s d t
$$

The kinetic energy of the moving fluid $T_{F}$ is considered. The velocity of the moving fluid $\vec{V}_{F}(s, t)$ has the form: $\vec{V}_{F}(s, t)=\vec{V}_{P}(s, t)+U_{*} \vec{\tau}^{0}(s, t)$. The kinetic energy of the moving fluid is the following:

$$
T_{F}=\frac{M_{1}}{2} \int_{0}^{L}\left\{\left(U_{*}+\frac{\partial u}{\partial t}+U_{*} \frac{\partial u}{\partial s}\right)^{2}+\left(\frac{\partial v}{\partial t}+U_{*} \frac{\partial v}{\partial s}\right)^{2}\right\} d s,
$$

The variation of the kinetic energy has the form:

$$
\begin{gathered}
\int_{t_{1}}^{t_{2}} \delta T_{F} d t=\int_{t_{1}}^{t_{2}}\left[M_{1} U_{*}\left(\frac{\partial \vec{r}_{L}}{\partial t}+U_{*} \vec{\tau}_{L}^{0}\right) \cdot \delta \vec{r}_{L}\right] d t- \\
M_{1} \int_{t_{1}}^{t_{2}} d t \int_{0}^{L} d s\left\{\delta u\left[\frac{\partial^{2} u}{\partial t^{2}}+2 U_{*} \frac{\partial^{2} u}{\partial t \partial s}+U_{*}^{2} \frac{\partial^{2} u}{\partial s^{2}}\right]+\delta v\left[\frac{\partial^{2} v}{\partial t^{2}}+2 U_{*} \frac{\partial^{2} v}{\partial t \partial s}+U_{*}^{2} \frac{\partial^{2} v}{\partial s^{2}}\right]\right\} .
\end{gathered}
$$

Following the variation methods [21], the equations $(8,7,6,5)$ are substituted into (2). Then the following system of the partial differential equations is obtained:

$$
\begin{gathered}
\frac{\partial^{2} M}{\partial s^{2}}+\left(M_{1}+m\right) \frac{\partial^{2} v}{\partial t^{2}}+2 M_{1} U_{*} \frac{\partial^{2} v}{\partial t \partial s}+M_{1} U_{*}^{2} \frac{\partial^{2} v}{\partial s^{2}}-\frac{\partial}{\partial s}\left[N \frac{\partial v}{\partial s}\right]-\frac{\partial}{\partial s}\left[M \frac{\partial^{2} v}{\partial s^{2}} \frac{\partial v}{\partial s}\right]+\frac{\partial^{2}}{\partial s^{2}}\left[\frac{M}{2}\left(\frac{\partial v}{\partial s}\right)^{2}\right]=0 \\
\frac{\partial N}{\partial s}-\left(M_{1}+m\right) \frac{\partial^{2} u}{\partial t^{2}}-2 M_{1} U_{*} \frac{\partial^{2} u}{\partial t \partial s}-M_{1} U_{*}^{2} \frac{\partial^{2} u}{\partial s^{2}}+\frac{\partial}{\partial s}\left[2 N \frac{\partial u}{\partial s}\right]=0 .
\end{gathered}
$$

The nonlocal elasticity of the nanotube is accounted by the equation [17]: $\sigma_{X X}-\left(e_{0} a\right)^{2} \frac{\partial^{2} \sigma_{X X}}{\partial s^{2}}=E \varepsilon_{X X}$, where $\sigma_{X X}, \varepsilon_{X X}$ are stresses and strains; $E$ is Young's modulus; $a$ is internal characteristic length; $e_{0}$ is a constant. The resultant longitudinal force and the resultant bending moment are determined as $N=\int_{A} \sigma_{X X} d A ; \quad M=\int_{A} y \sigma_{X X} d A$, where $A$ is nanotube cross section. Strains of the arbitrary point of the nanotube are calculated from the following equation: $\varepsilon_{X X}=\varepsilon+y k$. Then the resultant longitudinal force and resultant bending moment satisfy the following equation: 


$$
N-\left(e_{0} a\right)^{2} \frac{\partial^{2} N}{\partial s^{2}}=E A \varepsilon ; M-\left(e_{0} a\right)^{2} \frac{\partial^{2} M}{\partial s^{2}}=E I k,
$$

where $I$ is cross section inertia moment.

The equations (11) are substituted into the equations $(9,10)$. Then the following equations of the nanotube motions are obtained:

$$
\begin{gathered}
E I \frac{\partial^{4} v}{\partial s^{4}}+\left(M_{1}+m\right) \frac{\partial^{2} v}{\partial t^{2}}+2 M_{1} U_{*} \frac{\partial^{2} v}{\partial t \partial s}+M_{1} U_{*}^{2} \frac{\partial^{2} v}{\partial s^{2}}-\left(e_{0} a\right)^{2}\left[\left(M_{1}+m\right) \frac{\partial^{4} v}{\partial t^{2} \partial s^{2}}+2 M_{1} U_{*} \frac{\partial^{4} v}{\partial t \quad \partial s^{3}}+M_{1} U_{*}^{2} \frac{\partial^{4} v}{\partial s^{4}}\right] \\
+F_{V}=0 ; \\
E A \frac{\partial^{2} u}{\partial s^{2}}-\left(M_{1}+m\right) \frac{\partial^{2} u}{\partial t^{2}}-2 M_{1} U_{*} \frac{\partial^{2} u}{\partial t \partial s}-M_{1} U_{*}^{2} \frac{\partial^{2} u}{\partial s^{2}}+ \\
\left(e_{0} a\right)^{2}\left\{\left(M_{1}+m\right) \frac{\partial^{4} u}{\partial t^{2} \partial s^{2}}+2 M_{1} U_{*} \frac{\partial^{4} u}{\partial t \partial s^{3}}+M_{1} U_{*}^{2} \frac{\partial^{4} u}{\partial s^{4}}\right\}+F_{U}=0,
\end{gathered}
$$

where

$$
\begin{gathered}
F_{V}=\frac{E I}{2} \frac{\partial^{2}}{\partial s^{2}}\left[\frac{\partial^{2} v}{\partial s^{2}}\left(\frac{\partial v}{\partial s}\right)^{2}\right]-\left\{\frac{\partial}{\partial s}-\left(e_{0} a\right)^{2} \frac{\partial^{3}}{\partial s^{3}}\right\}\left[N \frac{\partial v}{\partial s}+M \frac{\partial^{2} v}{\partial s^{2}} \frac{\partial v}{\partial s}-\frac{\partial}{\partial s}\left(\frac{M}{2}\left(\frac{\partial v}{\partial s}\right)^{2}\right)\right] ; \\
F_{U}=E A \frac{\partial}{\partial s}\left\{\left(\frac{\partial u}{\partial s}\right)^{2}+0.5\left(\frac{\partial v}{\partial s}\right)^{2}\right\}+2\left\{\frac{\partial}{\partial s}-\left(e_{0} a\right)^{2} \frac{\partial^{3}}{\partial s^{3}}\right\}\left[N \frac{\partial u}{\partial s}\right] .
\end{gathered}
$$

The resultant longitudinal force and the resultant bending moments (11) are substituted into the nonlinear functions $F_{V}, F_{U}$ without accounting nonlocal elasticity. As the result, it is obtained:

$$
\begin{gathered}
F_{V}=\frac{E I}{2} \frac{\partial^{2}}{\partial s^{2}}\left[\frac{\partial^{2} v}{\partial s^{2}}\left(\frac{\partial v}{\partial s}\right)^{2}\right]-\left\{\frac{\partial}{\partial s}-\left(e_{0} a\right)^{2} \frac{\partial^{3}}{\partial s^{3}}\right\} R_{*} \\
F_{U}=E A \frac{\partial}{\partial s}\left\{\left(\frac{\partial u}{\partial s}\right)^{2}+0.5\left(\frac{\partial v}{\partial s}\right)^{2}\right\}+2 E A\left\{\frac{\partial}{\partial s}-\left(e_{0} a\right)^{2} \frac{\partial^{3}}{\partial s^{3}}\right\}\left\{\left(\frac{\partial u}{\partial s}\right)^{2}+\left(\frac{\partial u}{\partial s}\right)^{3}+0.5 \frac{\partial u}{\partial s}\left(\frac{\partial v}{\partial s}\right)^{2}\right\} \\
R_{*}=E A \frac{\partial v}{\partial s}\left[\frac{\partial u}{\partial s}+\left(\frac{\partial u}{\partial s}\right)^{2}+0.5\left(\frac{\partial v}{\partial s}\right)^{2}\right]+E I \frac{\partial v}{\partial s}\left(\frac{\partial^{2} v}{\partial s^{2}}\right)^{2}-\frac{E I}{2} \frac{\partial}{\partial s}\left[\frac{\partial^{2} v}{\partial s^{2}}\left(\frac{\partial v}{\partial s}\right)^{2}\right] .
\end{gathered}
$$

The nonlinear dynamical system (12) is rewritten with respect to the following dimensionless variables and the parameters:

$$
(\tilde{u}, \tilde{v})=\frac{1}{R}(u, v) ; \eta=\frac{s}{L} ; \tau=\sqrt{\frac{E I}{\left(m+M_{1}\right) L^{4}}} t ; \bar{U}_{*}=\sqrt{\frac{M_{1} L^{2}}{E I}} U_{*} ; e_{n}=\frac{e_{0} a}{L} ; \varepsilon=\frac{\rho^{2}}{L^{2}} ; \alpha=\frac{R}{L} ; \gamma=\alpha \sqrt{\frac{M_{1}}{m+M_{1}}},
$$

where $\rho=\sqrt{\frac{I}{A}}$ is cross section radius of gyration; $R$ is radius of the nanotube middle surface. The system of the partial differential equations (12) with respect to the dimensionless variables and the parameters (13) takes the form:

$$
\begin{gathered}
\frac{\partial^{4} \tilde{v}}{\partial \eta^{4}}+\frac{\partial^{2} \tilde{v}}{\partial \tau^{2}}+2 \bar{U}_{*} \frac{\gamma}{\alpha} \frac{\partial^{2} \tilde{v}}{\partial \eta \partial \tau}+\bar{U}_{*}^{2} \frac{\partial^{2} \tilde{v}}{\partial \eta^{2}}-e_{n}^{2}\left\{\frac{\partial^{4} \tilde{v}}{\partial \eta^{2} \partial \tau^{2}}+2 \bar{U}_{*} \frac{\gamma}{\alpha} \frac{\partial^{4} \tilde{v}}{\partial \eta^{3} \partial \tau}+\bar{U}_{*}^{2} \frac{\partial^{4} \tilde{v}}{\partial \eta^{4}}\right\}+\tilde{F}_{V}=0 \\
\frac{\partial^{2} \widetilde{u}}{\partial \eta^{2}}-\varepsilon \frac{\partial^{2} \widetilde{u}}{\partial \tau^{2}}-2 \varepsilon \frac{\gamma}{\alpha} \bar{U}_{*} \frac{\partial^{2} \widetilde{u}}{\partial \eta}-\varepsilon \bar{U}_{*}^{2} \frac{\partial^{2} \widetilde{u}}{\partial \eta^{2}}+\varepsilon e_{n}^{2}\left\{\frac{\partial^{4} \widetilde{u}}{\partial \eta^{2} \partial \tau^{2}}+2 \frac{\gamma}{\alpha} \bar{U}_{*} \frac{\partial^{4} \widetilde{u}}{\partial \eta^{3} \partial \tau}+\bar{U}_{*}^{2} \frac{\partial^{4} \widetilde{u}}{\partial \eta^{4}}\right\}+\tilde{F}_{U}=0
\end{gathered}
$$

where

$$
\begin{gathered}
\tilde{F}_{V}=\frac{\alpha^{2}}{2} \frac{\partial^{2}}{\partial \eta^{2}}\left[\left(\frac{\partial \tilde{v}}{\partial \eta}\right)^{2} \frac{\partial^{2} \tilde{v}}{\partial \eta^{2}}\right]-\left\{\frac{\partial}{\partial \eta}-e_{n}^{2} \frac{\partial^{3}}{\partial \eta^{3}}\right\} \tilde{R}_{*} ; \\
\tilde{F}_{U}=\alpha \frac{\partial}{\partial \eta}\left\{\left(\frac{\partial \tilde{u}}{\partial \eta}\right)^{2}+\frac{1}{2}\left(\frac{\partial \tilde{v}}{\partial \eta}\right)^{2}\right\}+2 \alpha\left\{\frac{\partial}{\partial \eta}-e_{n}^{2} \frac{\partial^{3}}{\partial \eta^{3}}\right\}\left[\left(\frac{\partial \tilde{u}}{\partial \eta}\right)^{2}+\alpha\left(\frac{\partial \tilde{u}}{\partial \eta}\right)^{3}+\frac{\alpha}{2} \frac{\partial \tilde{u}}{\partial \eta}\left(\frac{\partial \tilde{v}}{\partial \eta}\right)^{2}\right] ; \\
\tilde{R}_{*}=\frac{1}{\varepsilon}\left[\alpha \frac{\partial \tilde{u}}{\partial \eta}+\alpha^{2}\left(\frac{\partial \tilde{u}}{\partial \eta}\right)^{2}+\frac{\alpha^{2}}{2}\left(\frac{\partial \tilde{v}}{\partial \eta}\right)^{2}\right] \frac{\partial \tilde{v}}{\partial \eta}-\frac{\alpha^{2}}{2} \frac{\partial^{3} \tilde{v}}{\partial \eta^{3}}\left(\frac{\partial \tilde{v}}{\partial \eta}\right)^{2} ;
\end{gathered}
$$

Thus, the system of two partial differential equations is obtained. This system describes the longitudinal-flexural 
self- sustained vibrations of the nanotube conveying fluid. These self-sustained vibrations occur owing to the instability of the trivial equilibrium of the nanotube. This dynamic instability is described by the system of the linear partial differential equations.

\section{DYNAMIC INSTRABILITY OF EQUILIBRIUM}

The trivial equilibrium $(\tilde{u}=\tilde{v}=0)$ of the nanotube conveying fluid is analyzed. The flexural vibrations, which are described by the equations (14), can be the origin of the dynamic instability. Note, that the equations of the longitudinal and the flexural vibrations (14) are uncoupled in the linear approximation. The nonlinear terms are not accounted to analyze the dynamic stability. The motions of the flexural vibrations are treated. They are approximated as:

$$
\tilde{v}=\sum_{j=1}^{N_{1}} q_{j}^{(v)}(\tau) V_{j}(\eta),
$$

where $V_{j}(\eta)$ are flexural eigenmodes of the cantilever beam. The Galerkin method is applied to the partial differential equation. Then the finite degrees of freedom linear dynamical system is derived with respect to the phase coordinates $\mathbf{z}=\left(\mathbf{q}^{(\mathbf{v})}, \mathbf{v}^{(\mathbf{v})}\right)=\left(q_{1}^{(v)}, \ldots, q_{N_{1}}^{(v)}, v_{1}^{(v)}=\dot{q}_{1}^{(v)}, \ldots, v_{N_{1}}^{(v)}=\dot{q}_{N_{1}}^{(v)}\right)$ as:

$$
\dot{\mathbf{z}}=\mathbf{D z} \text {, }
$$

where the matrix $\mathbf{D}$ has the following form:

$\mathbf{E}$ is identity matrix.

$$
\mathbf{D}=\left[\begin{array}{cc}
0 & \mathbf{E} \\
-\widetilde{\mathbf{K}} & -\widetilde{\mathbf{C}}
\end{array}\right] ; \widetilde{\mathbf{K}}=\boldsymbol{\Lambda}^{-1} \mathbf{K} ; \quad \tilde{\mathbf{C}}=\boldsymbol{\Lambda}^{-1} \mathbf{C} ;
$$

The characteristic exponents $\lambda$ are calculated to analyze stability of the trivial equilibrium. The solution of the dynamical system (16) has the form: $\mathbf{z}=\mathbf{z}_{*} \exp (\lambda \tau)$. The characteristic exponents are determined from the following eigenvalue problem:

$$
\mathbf{D} \mathbf{z}_{*}=\lambda \mathbf{z}_{*} .
$$

\section{FINITE DEGREES OF FREEDOM NONLINEAR DYNAMICAL SYSTEM}

In order to study the self-sustained vibrations of the system (14) the finite degrees of freedom model is derived. Then the flexural displacements are expanded in the form (15) and the longitudinal displacements take the form:

$$
\tilde{u}=\sum_{j=1}^{N_{2}} q_{j}^{(u)}(\tau) U_{j}(\eta)
$$

where $U_{j}$ are the eigenmodes of the longitudinal vibrations.

The system of the nonlinear partial differential equations (14) is transformed to the finite degrees of freedom nonlinear dynamical system to analyze the self-sustained vibrations of the nanotube conveying fluid. Then the expansions $(15,18)$ are substituted into the equations $(14)$ and the Galerkin technique is applied. The nonlinear finite degrees of freedom dynamical system is obtained in the following form:

$$
\begin{gathered}
\sum_{j=1}^{N_{1}} \Lambda_{\mu j} \ddot{q}_{j}^{(v)}+\sum_{j=1}^{N_{1}} K_{\mu j} q_{j}^{(v)}+\sum_{j=1}^{N_{1}} C_{\mu j} \dot{q}_{j}^{(v)}+\sum_{j_{1}=1}^{N_{1}} \sum_{j_{2}=1}^{j_{2} \leq j_{1}} \sum_{j_{3}=1}^{j_{3} \leq j_{2}} \alpha_{j_{1} j_{2} j_{3}}^{(\mu)} q_{j_{1}}^{(v)} q_{j_{2}}^{(v)} q_{j_{3}}^{(v)} \\
+\sum_{j_{1}=1}^{N_{2}} \sum_{j_{2}=1}^{N_{1}} \beta_{j_{1} j_{2}}^{(\mu)} q_{j_{1}}^{(u)} q_{j_{2}}^{(v)}+\sum_{j_{1}=1}^{N_{2}} \sum_{j_{2}=1}^{j_{2} \leq j_{1}} \sum_{j_{3}=1}^{N_{1}} \beta_{j_{1} j_{2} j_{3}}^{(\mu)} q_{j_{1}}^{(u)} q_{j_{2}}^{(u)} q_{j_{3}}^{(v)}=0 ; \\
\mu=1, \ldots, N_{1} ; \\
\tilde{\Lambda}_{\mu} \ddot{q}_{\mu}^{(u)}+\widetilde{K}_{\mu} q_{\mu}^{(u)}+\sum_{j=1}^{N_{2}} \tilde{C}_{\mu j} \dot{q}_{j}^{(u)}-\sum_{j_{1}=1}^{N_{2}} \sum_{j_{2}=1}^{j_{2} \leq j_{1}} \tilde{\alpha}_{j_{1} j_{2}}^{(\mu)} q_{j_{1}}^{(u)} q_{j_{2}}^{(u)}-\sum_{j_{1}=1}^{N_{1}} \sum_{j_{2}=1}^{j_{2} \leq j_{1}} \tilde{\beta}_{j_{1} j_{2}}^{(\mu)} q_{j_{1}}^{(v)} q_{j_{2}}^{(v)}- \\
\sum_{j_{1}=1}^{N_{2}} \sum_{j_{2}=1}^{j_{2} \leq j_{1}} \sum_{j_{3}=1}^{j_{3} \leq j_{2}} \delta_{j_{1} j_{2} j_{3}}^{(\mu)} q_{j_{1}}^{(u)} q_{j_{2}}^{(u)} q_{j_{3}}^{(u)}-\sum_{j_{1}=1}^{N_{2}} \sum_{j_{2}=1}^{N_{1}} \sum_{j_{3}=1}^{j_{3} \leq j_{2}} \tilde{\beta}_{j_{1} j_{2} j_{3}}^{(\mu)} q_{j_{1}}^{(u)} q_{j_{2}}^{(v)} q_{j_{3}}^{(v)}=0 ; \mu=1, \ldots, N_{2},
\end{gathered}
$$


where the matrixes elements $\Lambda_{\mu j}, K_{\mu j}, C_{\mu j}$ are treated in the previous sections; the values $\alpha_{j_{1} j_{2} j_{3}}^{(\mu)}, \beta_{j_{1} j_{2}}^{(\mu)}, \beta_{j_{1} j_{2} j_{3}}^{(\mu)}, \tilde{\alpha}_{j_{1} j_{2}}^{(\mu)}, \tilde{\beta}_{j_{1} j_{2}}^{(\mu)}, \delta_{j_{1} j_{2} j_{3}}^{(\mu)}, \tilde{\beta}_{j_{1} j_{2} j_{3}}^{(\mu)}$ depends on the system parameters.

Thus, the nonlinear dynamical system $(19,20)$, which describes the self-sustained vibrations of the nanotube conveying fluid, is derived. The harmonic balanced method [22] is used to study the self-sustained vibrations. Then the vibrations take the form:

$$
\begin{gathered}
q_{i}^{(v)}=A_{i}^{(v)}+A_{i}^{(v, s)} \sin (\omega \tau)+B_{i}^{(v)} \cos (\omega \tau) ; i=1, \ldots, N_{1} ; \\
q_{i}^{(u)}=A_{i}^{(u)}+A_{i}^{(u, s)} \sin (\omega \tau)+B_{i}^{(u)} \cos (\omega \tau) ; i=1, \ldots, N_{2} .
\end{gathered}
$$

Note, that one amplitude parameter from $(21)$ for the autonomous system $(19,20)$ can be taken equal to zero. For example, $B_{1}^{(v)}=0$. In order to prove this, the motion $q_{1}^{(v)}$ is rewritten as: $q_{1}^{(v)}=A_{1}^{(v)}+\tilde{A}_{1} \sin (\omega \tau+\varphi)$. The dynamical system $(19,20)$ is autonomous. Therefore, the following change of the variable is used $\tau \rightarrow \tau+\frac{\varphi}{\omega}$. Then the equation $B_{1}^{(v)}=0$ is true.

The amplitude parameters (21) are merged into the vector $\mathbf{A}$ of $3\left(N_{1}+N_{2}\right)$ dimension: $\mathbf{A}=\left[A_{1}^{(v)}, A_{1}^{(v, s)}, \ldots, A_{N_{1}}^{(v)}, A_{N_{1}}^{(v, s)}, A_{N_{1}}^{(v)}, A_{1}^{(u)}, \ldots, A_{N_{2}}^{(u, s)}, A_{N_{2}}^{(u)}\right]$. Following the harmonic balanced method, the solutions (21) are substituted into the equations $(19,20)$ and the amplitudes at the same harmonics are equated. As a result, the system of $3\left(N_{1}+N_{2}\right)$ nonlinear algebraic equations is presented in the form:

$$
G_{j}\left(A, \omega, \bar{U}_{*}\right)=0 ; j=1, \ldots, 3\left(N_{1}+N_{2}\right) \text {. }
$$

The goal of these calculations is to obtain the bifurcation diagrams, which show the dependence of the limit cycles amplitudes on the fluid velocity $\bar{U}_{*}$. In order to obtain this dependence, the system of the nonlinear algebraic equations (22) is solved numerically for different values of the parameter $\bar{U}_{*}$.

\section{RESULTS OF NUMERICAL SIMULATIONS Analysis of equilibrium stability}

The CNT, which is treated in [2], is considered to verify the method of dynamic instability calculations. The density of CNT material and the Young modulus are the following: $\rho_{C N T}=2.39 \mathrm{~g} / \mathrm{cm}^{3}$ and $E=1 \mathrm{TPa}$. The fluid density is taken as: $\rho_{W}=1.0 \mathrm{~g} / \mathrm{cm}^{3}$. The thickness of the nanotube and the radius of the middle surface are $h=$ $20 \mathrm{~nm}$ and $R=30 \mathrm{~nm}$. The nanotube with these parameters is called case I.

The origin of the nanotube dynamic instability with the aspect ratio $\frac{L}{2 R}=66.67$ is analyzed. The nonlocal elasticity is not accounted in these calculations $\left(e_{0} a=0\right)$. The fluid velocity, when the dynamic instability starts, is called critical. This velocity is denoted by $U_{c r}$. The dynamical system (16) with 2, 3, 4, 5 and 6 degrees of freedom is analyzed to calculate the fluid critical velocity. The fluid critical velocities $U_{c r}$ are presented in Table 1 .

Table 1.

The fluid critical velocities (case I)

\begin{tabular}{|l|l|l|l|l|c|}
\hline aspect ratio, $\frac{L}{2 R}$ & $N_{1}$ & $U_{c r}, \mathrm{~m} / \mathrm{s}$ & $\widetilde{U}_{c r}, \mathrm{~m} / \mathrm{s}$ & $\delta$ & $U_{c r}^{(\text {nonl })}, \mathrm{m} / \mathrm{s}$ \\
\hline 66.67 & 2 & 1492.35 & \multirow{4}{*}{1510} & 0.011 & - \\
\hline 66.67 & 3 & 1515.32 & & 0.0035 & 1515.01 \\
\hline 66.67 & 4 & 1512.87 & 0.0019 & 1512.87 \\
\hline 66.67 & 5 & 1511.95 & & 0.0013 & 1512.25 \\
\hline 66.67 & 6 & 1512.56 & & 0.0017 & 1511.95 \\
\hline 13.33 & 2 & 7461.76 & \multirow{5}{*}{7560} & 0.013 & - \\
\hline 13.33 & 3 & 7576.57 & & 0.0022 & 7576.58 \\
\hline 13.33 & 4 & 7564.33 & & $5.73 \mathrm{e}-4$ & 7564.33 \\
\hline 13.33 & 5 & 7559.74 & & $3.44 \mathrm{e}-5$ & 7559.74 \\
\hline 13.33 & 6 & 7561.26 & & $1.67 \mathrm{e}-4$ & 7561.27 \\
\hline \multirow{nnnny}{nnnny}{} & & & &
\end{tabular}

The values of the nanotube aspect ratio $\frac{L}{2 R}$ are shown in the first column of the Table and the numbers of the system (16) degrees of freedom $N_{1}$ are presented in the second column of the Table. The fluid critical velocities $U_{c r}$ are shown on the third column. The values of the critical velocities, which are published in the paper [2], are presented in the fourth column. The relative differences of the critical velocities are calculated as: $\delta=\frac{\left|U_{c r}-\widetilde{U}_{c r}\right|}{\widetilde{U}_{c r}}$. Thus, the critical velocities of the nanotubes with the aspect ratio $\frac{L}{2 R}=66.67$ are close for the dynamical systems (16) with $3 \div 6$ degrees 
of freedom. Moreover, these critical velocities are very close to the data, which are published in [2]. Thus, the convergence of the critical flow velocities is observed, when the number of degrees of freedom is increased.

The fluid critical velocities in the nanotube with the aspect ratio $\frac{L}{2 R}=13.33$ are analyzed. The nonlocal elasticity is not taken into account $\left(e_{0} a=0\right)$. The results of the critical fluid velocity calculations are shown in Table 1 . As follows from the Table, the results, which are obtained from $3 \div 6$ degrees of freedom dynamical system (16), and the data from [2] are close. Thus, the convergence of the obtained results is observed.

Table 2.

The fluid critical velocities (case II)

\begin{tabular}{|l|l|l|l|l|}
\hline aspect ratio, $\frac{L}{2 R}$ & $N_{1}$ & $U_{c r}, \mathrm{~m} / \mathrm{s}$ & $\widetilde{U}_{c r}, \mathrm{~m} / \mathrm{s}$ & \multicolumn{1}{c|}{$\delta$} \\
\hline 55.56 & 2 & 1169.95 & & 0.14 \\
\hline 55.56 & 3 & 1385.91 & \multirow{4}{*}{1360} & 0.019 \\
\hline 55.56 & 4 & 1377.09 & 0,012 \\
\hline 55.56 & 5 & 1363.88 & & 0.0028 \\
\hline 55.56 & 6 & 1361.91 & & 0.0014 \\
\hline 11.11 & 2 & 5850.53 & \multirow{5}{*}{6800} & 0,14 \\
\hline 11.11 & 3 & 6928.77 & & 0,018 \\
\hline 11.11 & 4 & 6885.49 & 0,013 \\
\hline 11.11 & 5 & 6819.43 & & 0,0014 \\
\hline 11.11 & 6 & 6809.55 & & 0,0014 \\
\hline
\end{tabular}

The nanotube with the radius of the middle surface $R=45 \mathrm{mn}$ and $h=10 \mathrm{~nm}$ is considered. The density of the nanotube material, fluid and the Young modulus are equal to the corresponding parameters of the case $\mathrm{I}$. The nanotube with such parameters is called case II. The dynamic instability of this nanotube is analyzed. The results of the critical velocities calculations for the nanotubes with the aspect ratio $\frac{L}{2 R}=55.56$ are presented in Table 2 . The designation of the Tables 1 and 2 columns are the same. The fluid critical velocities, which are obtained from $4 \div 6$ degrees of freedom dynamical system (16), and the ones from the paper [2] are close. The results of the critical velocities calculations for the nanotube with the aspect ratio $\frac{L}{2 R}=11.11$ are shown on Table 2 too. As follows from this Table, $4 \div 6$ degrees of freedom are enough to predict the critical fluid velocities. Thus, the convergence of the critical velocities values is obtained, when the number of degrees of freedom $N_{1}$ is increased.

As follows from the numerical analysis, if the fluid velocity $\bar{U}_{*}$ and the critical velocity $\bar{U}_{c r}$ satisfy the inequality:

$$
\bar{U}_{*}>\bar{U}_{c r},
$$

then the dynamic instability of the trivial equilibrium is observed.

\section{Self-sustained vibrations analysis}

The geometrical nonlinear longitudinal-flexural self-sustained vibrations of the nanotube are analyzed. The following parameters of the nanotube are used:

$h=20 \mathrm{~nm} ; E=1 \mathrm{TPa} ; R=30 \mathrm{~nm} ; \rho_{W}=1 \mathrm{~g} / \mathrm{cm}^{3} ; \frac{L}{2 R}=66.67 ; e_{0} a=0.934 \mathrm{mn} ; R_{\text {ext }}=40 \mathrm{~nm} ; R_{\text {int }}=20 \mathrm{~nm}$,

where $R_{\text {ext }}$ is external radius of the nanotube; $R_{\text {int }}$ is internal radius of nanotube. The dynamic instability of this nanotube is treated at the beginning of this Section. In order to analyze the numerical results, the harmonic approximation of the self-sustained vibrations (21) takes the form:

$$
q_{i}^{(v)}=A_{i}^{(v)}+A_{*}^{(i)} \sin \left(\omega \tau+\varphi_{i}\right) ; q_{i}^{(u)}=A_{i}^{(u)}+B_{*}^{(i)} \sin \left(\omega \tau+\theta_{i}\right) .
$$

The harmonic balanced method is applied to analyze the self-sustained vibrations of the nanotube. The system of the nonlinear algebraic equations (22) is solved numerically for different values of the fluid motions $\bar{U}_{*}$. The calculations are performed with $N_{1}=5 ; N_{2}=4$ of the expansions $(15,18)$. Thus, the nonlinear dynamical system consists of five equations (19) and four equations (20). Therefore, the system of the nonlinear algebraic equations (22) has dimension 27.

As follows from the numerical analysis, the self-sustained vibrations are originated at the fluid critical velocity $\bar{U}_{*}=\bar{U}_{c r}$. If the fluid velocity $\bar{U}_{*}$ is increased and passed through the value $\bar{U}_{c r}$, the nanotube trivial equilibrium loses stability. The Hopf bifurcation takes place in the point of the stability loss. The limit cycle originates in this point. The data of this limit cycle numerical simulations are treated. The self-sustained vibrations are approximated accurately by 
one harmonic (21). The flexural self-sustained vibrations $q_{i}^{(v)}$ have zero constant part $A_{i}^{(v)} \equiv 0$ and the longitudinal motions $q_{i}^{(u)}$ describe the static behavior of the nanotube: $B_{*}^{(i)}=0 ; A_{i}^{(u)} \neq 0$. The convergence of the solution (15) is analyzed. The results of the convergence analysis are presented in Table 3 , where the amplitudes of the self-sustained vibrations $A_{*}^{(i)}$ are shown for different values of the fluid motions. As follows from this Table, if the numbers of the generalized coordinates $q_{i}^{(v)}$ are increased, the amplitudes of the self-sustained vibrations are decreased quickly. As follows from Table 3, the following estimation is satisfied: $\frac{A_{*}^{(5)}}{A_{*}^{(1)}} \sim 10^{-3}$. Thus, the quick convergence of the solutions is observed.

Therefore, $N_{1}=5$ is enough to obtain the reliable results.

Table 3.

The convergence of the periodic vibrations

\begin{tabular}{|c|l|l|l|l|}
\hline & \multicolumn{1}{|c|}{$\bar{U}_{*}=6.6$} & $\bar{U}_{*}=6.2$ & $\bar{U}_{*}=5.8$ & $\bar{U}_{*}=5.4$ \\
\hline$A_{*}^{(1)}$ & 1.86592 & 1.52838 & 1.183594 & 0.8093442 \\
\hline$A_{*}^{(2)}$ & 0.79684 & 0.67386 & 0.540521 & 0.3840375 \\
\hline$A_{*}^{(3)}$ & 0.02912 & 0.02359 & 0.018422 & 0.0129016 \\
\hline$A_{*}^{(4)}$ & 0.01406 & 0.01078 & 0.007778 & 0.0049201 \\
\hline$A_{*}^{(5)}$ & 0.00248 & 0.00195 & 0.001445 & 0.0009400 \\
\hline
\end{tabular}

The bifurcation diagram of the self-sustained vibrations is shown on Fig. 2.

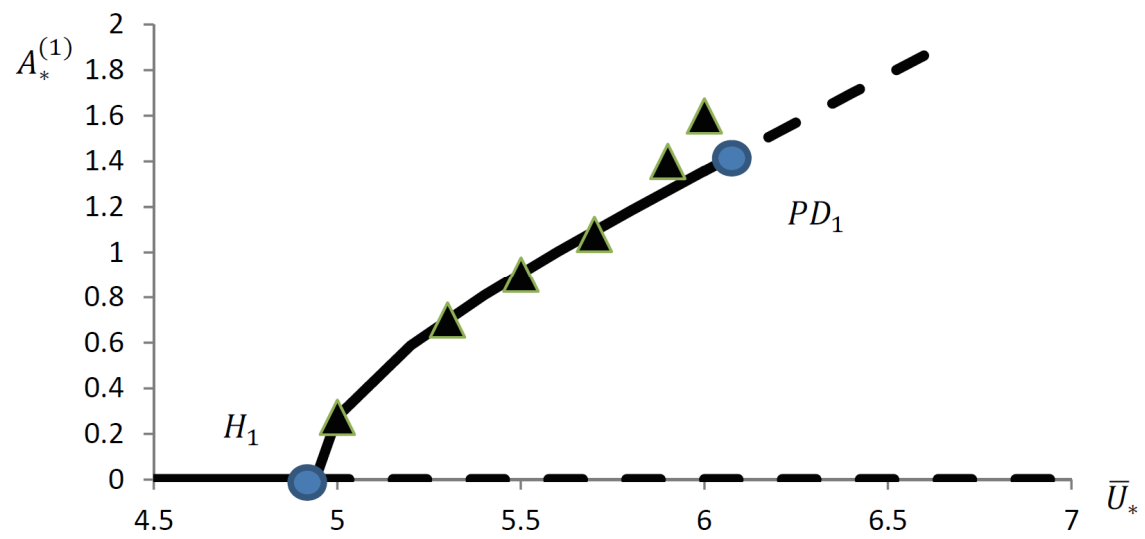

Fig.2. The bifurcation diagram of the self-sustained vibrations

The stable and unstable motions are shown by solid and dotted curves, respectively. The amplitudes of the vibrations $q_{1}^{(v)}$, which are denoted by $A_{*}^{(1)}$, are shown on Fig.2. The Hopf bifurcation $H_{1}$ (Fig. 2 ) is denoted by small circle. The trivial equilibriums are shown on Fig.2 by the lines, which coincide with abscissa axes. This equilibrium is stable at $\bar{U}_{*}<4.95$ and it is unstable at $\bar{U}_{*}>4.94$. The solid lines $\left(H_{1} P D_{1}\right)$ (Fig. 2) shows the stable self-sustained vibrations, which undergo the periodic doubling bifurcation in the point $P D_{1}$. The direct numerical integrations of the equations $(19,20)$ are performed to verify the results, which are obtained by the harmonic balanced method. These data are shown on Fig. 2 by small triangles. Moreover, the results, which are obtained by the harmonic balanced method and the direct numerical integrations, are close. If the fluid velocity is increased, the self-sustained vibrations frequency is decreased. The dependence of the self-sustained vibrations frequency $\omega$ on the fluid velocity $\bar{U}_{*}$ is shown on Fig.3.

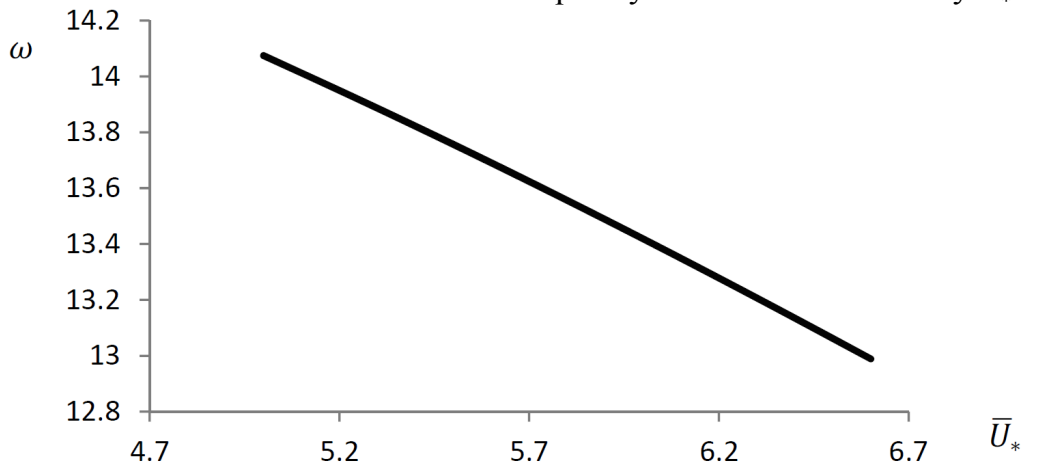

Fig.3. The dependence of the self-sustained vibrations frequency on the fluid velocity. 

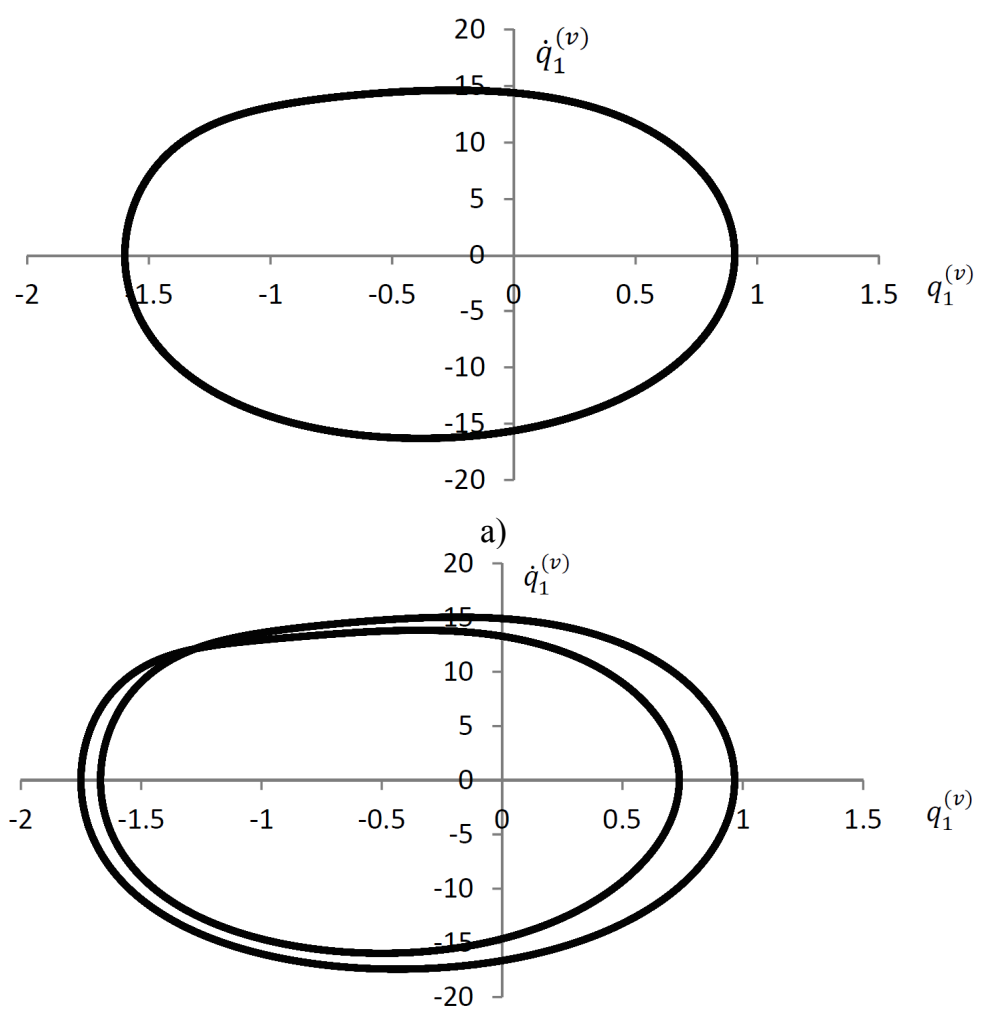

b)

Fig.4. The phase trajectories of the self-sustained vibrations at the following fluid velocities

$$
\mathrm{a}-\bar{U}_{*}=6.0 ; \mathrm{b}-\bar{U}_{*}=6.1 \text {. }
$$

The period-doubling bifurcation is observed in the point $P D_{1}$ (Fig. 2). Thereafter, the infinite sequence of the period-doubling bifurcations is observed. As a result of this infinite sequence, the chaotic motions originate. The direct numerical integrations of the equations $(19,20)$ are performed for different values of the flow velocities $\bar{U}_{*}$ to identify this bifurcation sequence. The results of such calculations are shown on Fig.4, where the phase trajectories on the plane $\left(q_{1}^{(v)}, \dot{q}_{1}^{(v)}\right)$ are shown. As follows from this Figure, the single-cycle is observed at $\bar{U}_{*}=6.0$. If the fluid velocity $\bar{U}_{*}$ is increased, the period-doubling bifurcation is observed. Fig. $4 \mathrm{~b}$ shows two-cycle at $\bar{U}_{*}=6.1$. If $\bar{U}_{*}$ is increased, one more period-doubling bifurcation is observed numerically. Four-cycle originates owing to this bifurcation. As a result of the infinite sequence of these bifurcations, the chaotic motions are observed. The Poincare sections are calculated to analyze the self-sustained chaotic vibrations. The intersections of the trajectory with the hypersurface

$$
\sum=\left\{\left(q_{1}^{(v)}, \ldots, q_{N_{1}}^{(v)}, q_{1}^{(u)}, \ldots, q_{N_{2}}^{(u)}, \dot{q}_{1}^{(v)}, \ldots, \dot{q}_{N_{1}}^{(v)}, \dot{q}_{1}^{(u)}, \ldots, \dot{q}_{N_{2}}^{(u)}\right) \in R^{2 N_{1}+2 N_{2}} \mid \dot{q}_{1}^{(v)}=0\right\}
$$

are determined numerically. The Poincare sections of the chaotic self-sustained vibrations at $\bar{U}_{*}=6.2$ are shown on Fig.5. The strange attractor on the planes $\left(q_{2}^{(v)}, q_{3}^{(v)}\right)$ is shown on this Figure. As an example, Fig.6 shows the chaotic self-sustained vibrations $q_{1}^{(v)}(t)$ at the fluid velocity $\bar{U}_{*}=6.2$.

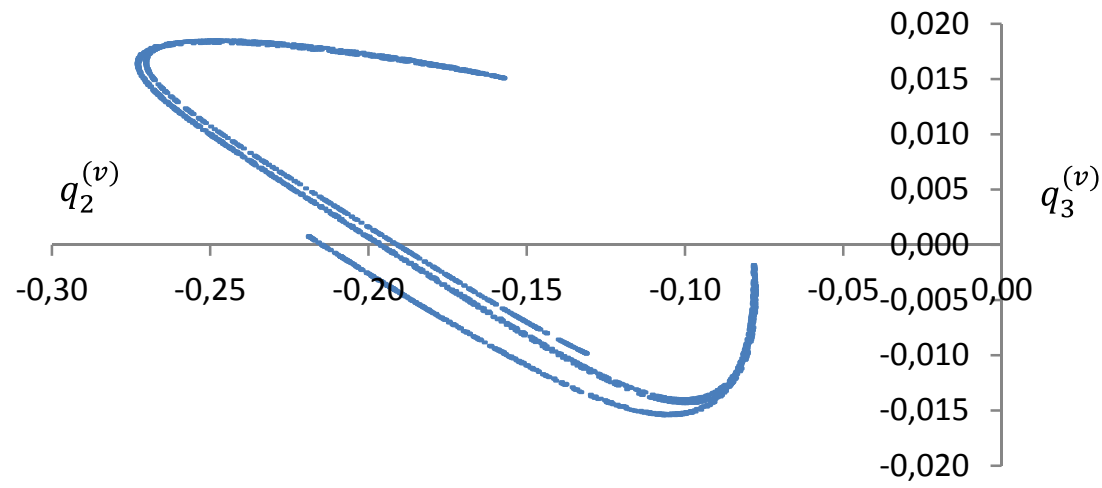

Fig.5. The projections of the Poincare sections at $\bar{U}_{*}=6.2$ on the planes $\left(q_{2}^{(v)}, q_{3}^{(v)}\right)$. 


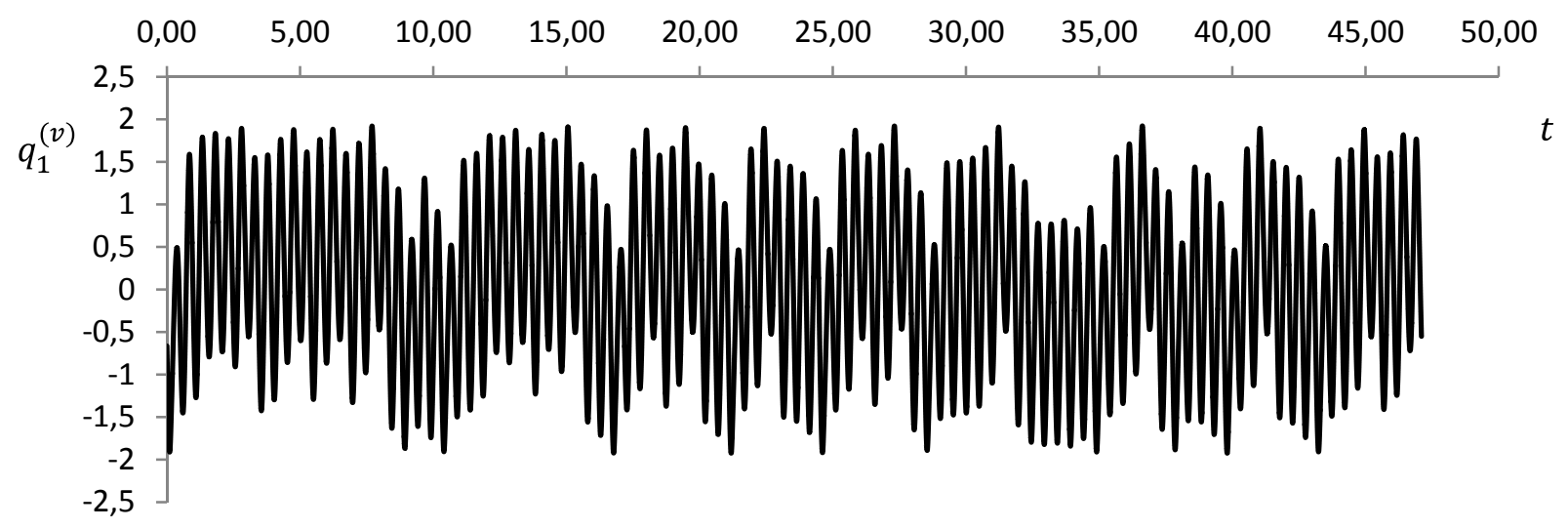

Fig.6. Chaotic self-sustained vibrations at $\bar{U}_{*}=6.2$.

\section{CONCLUSION}

The model of the longitudinal-flexural self-sustained vibrations of the cantilever nanotube conveying fluid is derived. This model is the system of the nonlinear ordinary differential equations. The system of two nonlinear partial differential equations, describing the longitudinal-flexural self-sustained vibrations, is obtained. The geometric nonlinearity and the nonlocal elasticity are accounted in this system.

The harmonic balanced method is applied to analyze the harmonic self-sustained vibrations in the nonlinear dynamical system. As a result of this method application, the calculations of the self-sustained vibrations are reduced to the system of the nonlinear algebraic equations with respect to the vibrations amplitudes.

The self-sustained vibrations of the nanotube conveying fluid are analyzed. The vibrations of the nanotube are close to monoharmonic. The harmonic balanced method with the monoharmonic approximation of the vibrations is used. In this case, the self-sustained vibrations are flexural and the nanotube static tension is observed in the longitudinal direction. If the fluid velocity is increased, these harmonic self-sustained vibrations undergo the infinite sequence of the period-doubling bifurcations and these self-sustained vibrations are transformed into chaotic ones.

\section{REFERENCES}

1. Yoon J., Ru C.Q., Mioduchowski A. Vibration and instability of carbon nanotubes conveying fluid // Comp. Scien. and Techn. 2005. - Vol. 65. - P. 1326-1336.

2. Yoon J., Ru C.Q., Mioduchowski A. Flow-induced flutter instability of cantilever carbon nanotubes // Int. J. of Solids and Struc. - 2006. - Vol. 43. - P. 3337-3349.

3. Wang L., Ni Q., Li M., Qian Q. The thermal effect on vibration and instability of carbon nanotubes conveying fluid // Phys. E. -2008. - Vol. 40. - P. 3179-3182.

4. Wang L., Ni Q. A reappraisal of the computational modeling of carbon nanotubes conveying viscous fluid // Mech. Res. Comm. - 2009. - Vol. 36. - P. 833-837.

5. Reddy C.D., Lu C., Rajendran S., Liew K.M. Free vibration analysis of fluid-conveying single-walled carbon nanotubes // Appl. Phys. Lett. - 2007. - Vol. 90. - 133122.

6. Khosravian N., Rafii-Tabar H. Computational modeling of the flow of viscous fluids in carbon nanotubes // J. Phys. D: Appl. Phys. - 2007. - Vol. 40. - P. 7046-7052.

7. Wang L. Vibration and instability analysis of tubular nano- and micro-beams conveying fluid using nonlocal elastic theory // Phys. E. - 2009. - Vol. 41. - P. 1835-1840.

8. Lee H.-L., Chang W.-J. Free transverse vibration of the fluid-conveying single-walled carbon nanotube using nonlocal elastic theory // J. of Appl. Phy. - 2008. - Vol. 103. - 024302.

9. Lee H.-L., Chang W.-J. Vibration analysis of a viscous-fluid-conveying single-walled carbon nanotube embedded in an elastic medium // Phys. E. - 2009. - Vol. 41. - P. 529-532.

10. Ghavanloo E., Daneshmand F., Rafiei M. Vibration and instability analysis of carbon nanotubes conveying fluid and resting on a linear viscoelastic Winkler foundation // Phys. E. - 2010. - Vol. 42. - P. 2218-2224.

11. Chang W.-J., Lee H.-L. Free vibration of a single-walled carbon nanotube containing a fluid flow using the Timoshenko beam model // Phys. Lett. A. - 2009. - Vol. 373. - P. 982-985.

12. Chang T.-P., Liu M.-F. Small scale effect on flow-induced instability of double-walled carbon nanotubes // Europ. J. of Mech. A/Solids. - 2011. - Vol. 30. - P. 992-998.

13. Chang T.-P., Liu M.-F. Flow-induced instability of double-walled carbon nanotubes based on nonlocal elasticity theory // Phys. E. - 2011. - Vol. 43. - P. 1419-1426.

14. Yan Y., He X.Q., Zhang L.X., Wang C.M. Dynamic behavior of triple-walled carbon nanotubes conveying fluid // J. of Sound and Vibr. - 2009. - Vol. 319. - P.1003-1018.

15. He X.Q., Wang C.M., Yan Y., Zhang L.X., Nie G.H. Pressure dependence of the instability of multiwalled carbon nanotubes conveying fluids // Arch. Appl. Mech. - 2008. - Vol. 78. - P. 637-648.

16. Khosravian N., Rafii-Tabar H. Computational modeling of a non-viscous fluid flow in a multi-walled carbon nanotube modeled 
as a Timoshenko beam // Nanotechnology. - 2008. - Vol. 19. - 275703.

17. Peddieson J., Buchanan G.R., McNitt R.P. Application of nonlocal continuum models to nanotechnology // Int. J. of Engin. Sc. - 2003. - Vol. 41. - P. 305-312.

18. Eringen A.C., Edelen D.G.B. On nonlocal elasticity // Int. J. of Engin. Sc. - 1972. - Vol. 10. - P. 233-248.

19. Semler C., Li G.X., Païdoussis M.P. The non-linear equations of motion of pipes conveying fluid // J. of Sound and Vibr. 1994. - Vol. 169. - P. 577-599.

20. Benjamin T.B. Dynamics of a system of articulated pipes conveying fluid // Proc. of the Royal Soc. A. - 1961. - Vol. 261. P. 457-586.

21. Adali S. Variational principles for transversely vibrating multiwalled carbon nanotubes based on nonlocal Euler-Bernoulli beam model // Nano Letters. - 2009. - Vol. 9. - P. 1737-1741.

22. Avramov K.V., Borysiuk O.V. Nonlinear dynamics of one disk asymmetrical rotor supported by two journal bearings // Nonl. Dyn. - 2011. - Vol. 67. - P. 1201-1219. 